\title{
GLOBAL SUPPLY CHAIN RELATIONSHIP, LOCAL MARKET COMPETITION, AND SUPPLIERS' INNOVATION IN DEVELOPING ECONOMIES
}

\author{
Lei DING(1) ${ }^{*}$, Gamal ATALLAH(®2), Guoqiang SUN $^{3}$ \\ ${ }^{1}$ Faculty of Management Science and Engineering, Shanxi University \\ of Finance and Economics, Taiyuan, China \\ ${ }^{2}$ Department of Economics, University of Ottawa, Ottawa, Canada \\ ${ }^{3}$ Faculty of Management Science and Engineering, \\ Shanxi University of Finance and Economics, Taiyuan, China
}

Received 20 January 2021; accepted 28 June 2021; first published online 03 December 2021

\begin{abstract}
This article examines how suppliers' innovation in developing countries is affected by the interaction of vertical global supply chain relationships and horizontal market competition structure. We devised a bidirectional dynamic game model consisting of competing suppliers in a developing economy and an overseas buyer in a developed economy for innovation decision process in a suppliers cluster. Our research shows that global supply chain relationship is the primary factor to influence local cluster innovation and profit. Total innovation of the cluster is proved to be greater in global supply relationship with a powerful buyer than a non-powerful buyer. However, suppliers in a powerful buyer chain are not able to capture the value they created from innovation. Local competition structure plays its secondary role on cluster innovation through interaction with vertical chain relationship. Based on prior innovation research on either vertical supply chain power dynamics or horizontal competition intenseness, our study contributes as the first to employ a theoretical suppliers' innovation model for an integrative analysis encompassing both global and local power dynamics.
\end{abstract}

Keywords: innovation, clustering, global supply chain, market competition, game theory.

JEL Classification: C72.

\section{Introduction}

Embedding in Global supply chain has long been considered as one way for local suppliers to develop and upgrade. However, it is also noted that the fragmented production which has flowed over the past century has had its dark side. Besides an increasing tendency towards growing unequalisation (Kadarusman \& Nadvi, 2013; Kaplinsky, 2000; Pahl \& Timmer, 2020;

\footnotetext{
*Corresponding author. E-mail: dlimbic@163.com
} 
Zhu \& He, 2018), some suppliers in developing countries are found to be be locked in the low end of global supply with the lowest returns and the most intense competitive pressures (Gereffi, 2019; International Labour Office, 2003; Kaplinsky, 1993). Although there is widespread agreement that the most viable response for embedded suppliers is to "innovate and upgrade" - to make better products, make them more efficiently, or move into more skilled activities (Dong \& Sun, 2020; Kaplinsky, 2000; Porter, 1990; You \& Virtanen, 2020), the question remains of how can local suppliers in developing countries generate more innovation, giving the complex power dynamic context of vertical global supply chain relationship and horizontal market competition.

Several schools of thought have emphasized the local cluster determinants including "new economic geography," business studies, reginal science and innovation studies. Meanwhile, literatures on global production systems noticed that global buyers (whether agents, retailers or brand-name companies) have come to play an important role and thus emphasizes cross-border linkages (Gereffi \& Kaplinsky, 2001; Gereffi \& Korzeniewicz, 1994). It is recognized that there is a need to bring these two perspectives together, especially for the exportoriented clusters that are inserted into global value chains (Humphrey \& Schmitz, 2002). We extend this research by exploring how the interaction of global supply chain relationship and local market competition affects the ways in which local suppliers in a cluster generate innovation ${ }^{1}$.

Why is interaction of global and local power dynamics important? Cluster literature gives prime importance to the local interaction between local suppliers and institutions, while the global value chain research accords prime importance to the interaction between the global buyers. If this was just a matter of different emphases it would be easy to bring together the two approaches and simply regard them as complementary. However, the fusion is far from straightforward because the interaction with the global buyer tends to take place in the context of a very uneven relationship (Dallas et al., 2019; Humphrey \& Schmitz, 2002; RajReichert, 2020). This inequality transforms relationships and innovation trajectories.

In order to examine how uneven global chain relationship affects suppliers' innovation, we distinguish two basic global supply chain relationship patterns: vertical powerful buyer (VP) and vertical weak buyer (VW). In VP, there is asymmetry of power in favor of the global buyer who had a major influence not just on sales but also on innovation options open to suppliers. This relationship coincides with hierarchical and quasi hierarchy governance types in global value chain (GVC) literatures. In VW, the relationship between suppliers and buyer is more or less equal and innovation is open to the suppliers' choice. This occurs in arm'slength and networks governance in GVC literatures.

We also take a very different approach to cluster determinants. Instead of focusing on interaction between suppliers and institutions as previous cluster studies did, we explore the role of local market competition. Firms make innovation decisions not only with consideration of their global buyers, but also with expectations of other local supplier competitors. However, this role of inter-firm dynamics has been given much less attention in cluster literatures since Porter (1990). Our methodology includes theoretical game model building and

\footnotetext{
${ }^{1}$ Innovation here is used in the broad sense of firms acquiring capabilities which are new to them, even if they have existed elsewhere previously.
} 
numerical simulation. We focus on individual firms in a global supply chain as our primary unit of analysis. To our best knowledge, previous research applies either case or empirical study, and their unit of analysis is the cluster, the industry, the region or the nation (Giuliani et al., 2005; Humphrey \& Schmitz, 2000; Tewari, 2008). This leaves little room for theorizing about how firm-level decisions affect innovation and value capture by firms (Coe \& Yeung, 2015; Sako \& Zylberberg, 2017). Our study contributes as the first to build a game model as an integrative theoretical framework to coordinate vertical and horizontal power dynamics' influence on supplier innovation and its value capture. The underline base of our model includes theories from GVC governance, supply chain management and market structure research.

The remainder of this article is structured as follows. Section 1 overviews the essence of theory analyzing innovation performance under global and local inter-firm context and identifies the gap our article seeks to address. Section 2 describes basic concepts and assumptions at the heart of our model building. Section 3 presents four innovation models and their solution process. Section 4 discusses the results and gives comparisons of the 4 innovation models. Management implications are analyzed in Section 5. The last section offers a conclusion of the results presented herein.

\section{Innovation under global and local inter-firm power dynamics}

\subsection{Global buyer-supplier relationship and innovation: supply chain management vs GVC governance}

Both supply chain managements and global value chain approaches emphasize the importance of global inter-firm power dynamics on innovation. Vertical relationship is considered particularly crucial in the generation, transfer and diffusion of knowledge leading to innovation. A close tied relationship or governance has been conventionally associated with pro innovation (Hoegl \& Wagner, 2005; Revilla \& Villena, 2012). However, latest studies in both branches point out that a close tied relationship is not necessary or sufficient to innovation (Gereffi, 2019; Kim et al., 2015). Table 1 summarizes the essence of relative theories.

How buyer-supplier relationship affects innovation performance has been rigorously studied by researchers in the work on global supply chain management, particularly over the last two decades. The closely tied relationship has been conventionally associated with cooperative and innovation pro (Jap, 1999; Wilson, 1995), while the arms-length relationships has been equated to adversarial and anti-innovation (Ellram \& Cooper, 1990; Zaheer et al., 1998). However, it is recently argued that a closely tied relationship could have a dark side and is really distinct from a cooperative and innovation pro relationship, meanwhile an arms-length relationship also has advantages and is distinct from an adversarial and antiinnovation relationship. Kim and Choi (2015) coordinated concepts of relational posture and relational intensity and distinguished buyer-supplier relationship typology into four relationship types as "deep" (high relational intensity and cooperative posture), "sticky" (high relational intensity and adversarial posture), "transient" (low relational intensity and adversarial posture), and "gracious" (low relational intensity and cooperative posture). The "Gracious" type shows highest level of supplier innovation (mainly black-box innovation), 
Table 1. Global buyer-supplier relationship and innovation (source: authors' summary based on literatures)

\begin{tabular}{|l|l|l|}
\hline \multicolumn{1}{|c|}{$\begin{array}{c}\text { Comparative } \\
\text { contents }\end{array}$} & \multicolumn{1}{|c|}{ Supply chain management } & \multicolumn{1}{c|}{ GVC governance } \\
\hline $\begin{array}{l}\text { Term used for } \\
\text { vertical inter-firm } \\
\text { dynamics }\end{array}$ & Buyer-supplier relationship & Governance \\
\hline $\begin{array}{l}\text { Term used for } \\
\text { innovation }\end{array}$ & Innovation & Upgrading and innovation \\
\hline $\begin{array}{l}\text { Innovation } \\
\text { characterization }\end{array}$ & $\begin{array}{l}\text { Black-box innovation by supplier under } \\
\text { pull from buyer in gracious relationship } \\
\text { Gray-box development jointly by buyer } \\
\text { and supplier in deep relationship } \\
\text { White-box innovation driven by the buyer } \\
\text { in transcient relationship } \\
\text { Zebra innovation driven by the buyer in } \\
\text { sticky relationship }\end{array}$ & $\begin{array}{l}\text { Incremental upgrading through } \\
\text { learning by doing and the allocation } \\
\text { of new tasks by the chain's lead firm } \\
\text { Discontinuous or radical upgrading } \\
\text { by "organizational succession" } \\
\text { allowing entry into more complex } \\
\text { value chains }\end{array}$ \\
\hline Vertical dynamics & $\begin{array}{l}\text { Deep, sticky, transient, and gracious } \\
\text { relationship }\end{array}$ & $\begin{array}{l}\text { Arm's length, network, quasi- } \\
\text { hierarchy, and hierarchy governance }\end{array}$ \\
\hline Innovation pro & $\begin{array}{l}\text { Gracious relationship } \\
\text { Deep relationship } \\
\text { Temporary de-embedding }\end{array}$ & $\begin{array}{l}\text { Quasi-hierarchy governance } \\
\text { (for incremental upgrading) } \\
\text { Network governance } \\
\text { (for radical upgrading) }\end{array}$ \\
\hline Anti-innovation & $\begin{array}{l}\text { Transient relationship (low relational } \\
\text { intensity and adversarial posture) } \\
\text { Sticky relationship (high relational } \\
\text { intensity and adversarial posture) }\end{array}$ & $\begin{array}{l}\text { Quasi-hierarchy governance } \\
\text { (for radical upgrading) }\end{array}$ \\
\hline
\end{tabular}

followed by the "deep" relationship (gray-box innovation), while both "transient" and "sticky" relationship associate with low level of innovation (Kim \& Choi, 2015). Furthermore, some latest research move from static relationships to strategic evolution aspect of relationship and shows that temporary de-embedding could also improve innovation performance for both parties (Sting et al., 2019; Villena et al., 2020).

The literature on global value chain pays particular attention to the role of powerful lead firms on suppliers using term "governance", which is defined as "authority and power relationships that determine how financial, material, and human resources are allocated and flow within a chain" (Gereffi \& Korzeniewicz, 1994). Four types of governance are distinguished in global value chains: market relations, network, quasi-hierarchy and hierarchy (ownership of the supplying unit by the buyer). In market governance, buyer and supplier don't develop close relationship. Network and quasi-hierarchical governance emerge when the buyer seeks to define the product or the buyer is exposed to considerable risk if the supplier fails to perform. In hierarchy, the lead firm takes direct ownership of the supplying unit. Different forms of chain governance have different supplier upgrading implications. On implication for developing country suppliers, it was widely argued that insertion in a quasihierarchical chain offers very favorable conditions for fast process and product upgrading but hinders functional upgrading. In chains characterized by market-based relationships, 
process and product upgrading tend to be slower (not fostered by global buyers), but the road to functional upgrading is more open. Recent case studies challenges assumptions of linear or inevitable processes of upgrading, and introduced notion of downgrading and backslide, leading to a more complex view on how GVC governance influence upgrading and innovation (Gereffi, 2019).

\subsection{Local cluster dynamics and innovation: regional science, innovation systems, and market structure}

The importance of local cluster dynamics as a source of innovation has been particularly stressed in three lines of work: regional science (in particular the industrial district literature), innovation systems and market structure studies.

The regional science studies are largely derived from the experience of the "Third Italy" and other European experiences. Scholars conclude that the innovation and diffusion within the cluster are not solely the result of incidental synergies, the "industrial atmosphere," but are fostered by policy networks of public and private institutions (Amin \& Thrift, 1992; Bellandi, 1996; De Propris \& Lazzeretti, 2009; Humphrey \& Schmitz, 2000; Markusen, 1996). The literature concerned with technological development moved from a focus on the individual firm towards a greater concern with learning-by-interaction, leading to the studies of innovations systems which concerning more with the knowledge system, the importance of knowledge enhancing organizations, political ties and the creation of a region's material and institutional infrastructure(Gorzelany-Dziadkowiec et al., 2019; Jensen et al., 2007; Jurowetzki et al., 2018; Lundvall et al., 2002; Yu et al., 2019). Both sets of literature have been used to analyze local industrial innovation in developing countries. Their application has been characterized by the concentration on the interaction between local firms and local institutions. Distinct from the above two literatures, the work on market structure focus on market forces and dynamics, concerning whether competition incentivizes or discourages innovation. Despite abundant evidence from empirical studies, the shape and significance of this relationship and the direction of causality are inconclusive (De Elejalde et al., 2019; Dias et al., 2020; Lee, 2005; Shapiro, 2011). Table 2 summarizes and compares the above theories.

Table 2. Local cluster dynamics and innovation (source: authors' summary based on literatures)

\begin{tabular}{|l|l|l|l|}
\hline \multicolumn{1}{|c|}{$\begin{array}{c}\text { Comparative } \\
\text { contents }\end{array}$} & \multicolumn{1}{|c|}{ Regional science } & \multicolumn{1}{|c|}{ Innovation systems } & \multicolumn{1}{c|}{ Market structure } \\
\hline $\begin{array}{l}\text { Local cluster } \\
\text { dynamics }\end{array}$ & $\begin{array}{l}\text { Interaction between firms } \\
\text { and local institutions }\end{array}$ & $\begin{array}{l}\text { Role of local policy } \\
\text { networks }\end{array}$ & $\begin{array}{l}\text { Inter-firm market force } \\
\text { and dynamics }\end{array}$ \\
\hline $\begin{array}{l}\text { Innovation } \\
\text { characterization }\end{array}$ & $\begin{array}{l}\text { Innovation speed up by } \\
\text { support from public and } \\
\text { private institutions }\end{array}$ & $\begin{array}{l}\text { Innovation diffusion } \\
\text { through learning-by- } \\
\text { interaction and particularly } \\
\text { knowledge enhancing } \\
\text { organization at national, } \\
\text { regional and local level }\end{array}$ & $\begin{array}{l}\text { Innovation supported or } \\
\text { hindered by dynamism } \\
\text { of leading firms, local } \\
\text { rivalry and supplier } \\
\text { networks }\end{array}$ \\
\hline $\begin{array}{l}\text { Researching } \\
\text { scope }\end{array}$ & $\begin{array}{l}\text { Production system } \\
\text { Policy system }\end{array}$ & Knowledge system & Production system \\
\hline
\end{tabular}




\subsection{Interaction of global and local power dynamics}

The literatures on global chain and local clusters suggest quite different innovation opportunities and trajectories for suppliers in developing countries. Both emphasizes the importance of innovation in order to sustain incomes in the face of increasing competition in global markets, but the routes to this same end are different. We summarized the differences in Table 3. The local cluster literature emphasizes the need to improve co-operation and local policy network. Link with the wider world are frequently acknowledged, but they are weakly theorized. Overall, the external world is viewed as a market presenting competitive challenges that must be met through effort within the cluster. A risk-coping mechanism within the cluster makes these challenges easier to meet (Gorzelany-Dziadkowiec et al., 2019; Jurowetzki et al., 2018; Lundvall et al., 2002).

In contrast, the global supply chain and value chain literature both emphasize links with the external world, leaving the locality largely untheorized. Little attention is paid to the role of business associations, local inter-firm co-operation or local policy network. In other words, local level dynamics is downplayed, while vertical inter-firm governance within chains is emphasized. Innovation occurs as a result of learning by exporting, buyer promotion of the capabilities of developing country producers or by entering export markets. Inter-firm co-operation within the chain rather than within the locality is viewed as source of innovation (Humphrey \& Schmitz, 2000; Kim \& Choi, 2015; Sting et al., 2019; Villena et al., 2020). While local cluster analysis underrates foreign customers as source of innovation, the global chain approach downplays the role of local innovation determinants.

One distinct feature of suppliers in export-oriented clusters in developing economies is that these local actors simultaneously compete within the domestic cluster while trade with overseas buyers in global chains. Therefore, it is necessary to integrate cluster method with global supply chain approach. Although some empirical studies brought together local and global factors as participation in international markets, local competitors, consultants and universities etc. (Odei \& Stejskal, 2020), how local and global power dynamics interact and contribute to innovation of suppliers in developing countries has not been studied systematically except the early work of Humphrey and Schmitz. Their work distinguishes between

Table 3. Innovation under local vs global dynamics (source: authors' summary based on literatures)

\begin{tabular}{|l|l|l|}
\hline \multicolumn{1}{|c|}{$\begin{array}{c}\text { Innovation } \\
\text { determinants }\end{array}$} & \multicolumn{1}{|c|}{ Local clusters } & \multicolumn{1}{c|}{ Global chains } \\
\hline $\begin{array}{l}\text { Local } \\
\text { dynamics }\end{array}$ & $\begin{array}{l}\text { Close inter-firm co-operation } \\
\text { and active private and public } \\
\text { institutions. Risks attenuated by } \\
\text { local mechanisms }\end{array}$ & $\begin{array}{l}\text { Not discussed. Local inter-firm co-operation } \\
\text { and government policy largely ignored }\end{array}$ \\
\hline $\begin{array}{l}\text { Global } \\
\text { dynamics }\end{array}$ & $\begin{array}{l}\text { External relations not theorized, } \\
\text { or assumed (by default) to be } \\
\text { based on arm's length market } \\
\text { transactions }\end{array}$ & $\begin{array}{l}\text { Strong governance within the chain. } \\
\text { International trade increasingly managed } \\
\text { through inter-firm networks based } \\
\text { on quasi-hierarchical relations. Risks } \\
\text { attenuated by relationships within the chain }\end{array}$ \\
\hline
\end{tabular}


different kinds of global value chain and local cluster governance and shows by case studies that certain types of interaction of chain and cluster governance favor some forms of upgrading and innovation but not others (Humphrey \& Schmitz, 2000). Our research contributes as the first to extend the research into a theoretical game model involving both local and global actors. In addition, with regard to local determinants, concerns in early research are non-market factors as private associations and public institutions. In contrast, we take a different approach to focus on inter-firm market dynamics and market structures which have fundamental instead of incidental effect on innovations.

\section{Model formulation}

\subsection{Global supply chain relationship}

This study applies dynamic game models to analyze the process of supplier innovation. Game theory method is a standard tool of analysis and has been used frequently in the field of operational and economic research. The advantage of this approach is that it can picture the multi agent interaction vividly with different power structure and dynamics. Our research involves multi actors and both vertical and horizontal power structures, which makes game models a proper tool for exploring our researching subject. Here we consider a global supply chain with an overseas buyer in developed country and two local suppliers in a developing country. Suppliers are selling a homogeneous consumer product, like electronic appliances or vehicles, to the overseas buy. Global vertical relationship between the buyer and suppliers is distinguished as vertical powerful buyer (VP) and vertical non-powerful or weak buyer (VW). Table 4 gives an explanation of all abbreviation used in this article. In Case $\mathrm{VP}$, the buyer has a high degree of control over suppliers' operations and give direct request on cost-reducing innovation in order to pursue lower-cost production. This happens when the buyer has persisted cost-reducing market strategy and are constantly scouting for lower-cost production sites. Case VP could be found mostly in quasi-hierarchy governance in traditional GVC literature. In Case VW, the relationship between suppliers and buyer is more or less equal. The innovation process is an independent one and suppliers make their decision purely on their own interests and benefits. This happens when the suppliers have gained certain experience of global production and reached a certain level of competence. Case VW is common in network governance in GVC literature. There are still two other governance patterns in GVC theory as hierarchy and arm's length. Hierarchy buyers take direct ownership of developing country operations, thus is not relevant to our interest. Arm's length suppliers have clear capability and reputation in particular production area and could rarely be found in developing economies (Humphrey \& Schmitz, 2000). Therefore, our study omitted these two cases.

\section{Assumption 1}

The global supply chain's overseas buyers is either powerful to influence supplier's innovation process, or weak to leave the innovation to supplier's own decision. 


\subsection{Local cluster competition}

We follow classical cluster literatures' framework and classify local cluster competition structures into two types as cluster balanced competition (CB) vs cluster centralized competition (CC). In Case $\mathrm{CB}$, suppliers have equal market power and compete in a Cournot game. Examples of Case CB are Italian clusters consisting of small and medium sized firms (Humphrey \& Schmitz, 2000). In Case CC, we assume that a large firm emerge and compete with other small firms in a Stackelberg game. This type reflects the clusters referred to as hub-andspoke clusters in which one or several large local lead firms dominate the activities of the smaller firms in the cluster. Examples are clusters in the German state of Baden-Wurttemberg (Sabel, 1989; Schmitz, 1992). Case CB reflects the situation in early stages of a local cluster, while Case CC reflects a matured local cluster when external buyers looked for much larger volumes of standardized products and led to the growth of large firms.

\section{Assumption 2}

Local cluster's competition structure is either a CB type, where suppliers have equal market power and compete in a Cournot game, or a CC type, where a large firm and followers compete in Stackelberg quantity game.

\subsection{Innovation and game order}

While supply chain management research uses the term "innovation," most GVC literature refers to "upgrading." As Sako and Zylberberg (2017) noted, these two terms have similar nature and "upgrading can be characterized as one type of innovative activity." In this study, we favor innovation for its broader scope and define innovation as a process of applying new technology to reduce unit cost of products. On one hand, this definition helps with the convenience of model deduction. On the other hand, cost-reducing innovations are the most cases of incremental upgrading for suppliers in developing economies (Odei \& Stejskal, 2020) and thus are of great importance to our interests. Therefore, we define supplier innovation as a process of applying new technology to reduce the unit cost of the product.

\section{Assumption 3}

Applying new technology reduces the unit cost of the product as $c_{s i}=\alpha-x_{s i}-\beta x_{s j}$.

Here $c_{s i}$ is the unit cost of supplier $i, x_{s i}, x_{s j}$ are innovation output of supplier $i$ and supplier $j$. The coefficient $\beta$ denotes the magnitude of exogenous involuntary innovation spillover. Spillover has been viewed as an important way of innovation infusion in a cluster. It happens through multiple channels. Enterprise managers will visit the factories and laboratories of their peers, enterprise employees will socialize or flow in different companies in the same industry, and firms have the same upstream suppliers and downstream buyers. Therefore, a supplier's innovation output also indirectly brings down the unit cost of other suppliers that have not conducted innovation. Since we assume that the innovation only brings down unit cost, the consumers' buying intention is affected primarily by product price as in the following linear inverse demand function. 
Table 4. Notation and abbreviations

\begin{tabular}{|c|c|}
\hline Notation & Definition \\
\hline $\mathrm{VP}$ & Cases with vertical powerful buyer \\
\hline VW & Cases with vertical non-powerful or weak buyer \\
\hline $\mathrm{CC}$ & Cases with a local cluster of centralized supplier power \\
\hline $\mathrm{CB}$ & Cases with a local cluster of balanced supplier power \\
\hline VPCB & Cases with vertical powerful buyer and a local cluster of balanced supplier power \\
\hline VWCB & $\begin{array}{l}\text { Cases with vertical weak or non-powerful buyer and a local cluster of balanced supplier } \\
\text { power }\end{array}$ \\
\hline VPCC & Cases with vertical powerful buyer and a local cluster of centralized supplier power \\
\hline VWCC & Cases with vertical weak buyer and a local cluster of centralized supplier power \\
\hline$c_{s i}$ & Unit cost of the product \\
\hline$x_{s i}$ & Innovation output of supplier $i$ \\
\hline$x_{s j}$ & Innovation output of supplier $j$ \\
\hline$\beta$ & Magnitude of exogenous involuntary innovation spillover \\
\hline$p$ & Unit selling price of the product to consumers \\
\hline$q_{s i}$ & Product output of supplier $i$ \\
\hline$q_{s j}$ & Product output of supplier $j$ \\
\hline$\Pi_{O B}$ & Profit of the overseas buyer \\
\hline$w$ & Wholesale price offered by the buyer to suppliers \\
\hline$\lambda$ & $\begin{array}{l}\text { A rule of thumb parameter which keeps the wholesale price as a proportion of final } \\
\text { selling price in the consumer market }\end{array}$ \\
\hline$\Pi_{s i}$ & Profit of the local supplier $i$ \\
\hline$\Pi_{s j}$ & Profit of the local supplier $j$ \\
\hline$\theta$ & Magnitude of innovation cost \\
\hline$\theta x_{s i}^{2}$ & Innovation expenditure to achieve the innovation output $x_{s i}$ \\
\hline$\theta x_{s j}^{2}$ & Innovation expenditure to achieve the innovation output $x_{s j}$ \\
\hline$X_{S 1 S 2}^{V P C C}$ & Total supplier cluster innovation of case VPCC \\
\hline$X_{S 1 S 2}^{V P C B}$ & Total supplier cluster innovation of case VPCB \\
\hline$X_{S 1 S 2}^{V W C C}$ & Total supplier cluster innovation of case VWCC \\
\hline$X_{S 1 S 2}^{V W C B}$ & Total supplier cluster innovation of case VWCB \\
\hline$\Pi_{S 1 S 2}^{V P}$ & Total supplier cluster profit of case VP \\
\hline$\Pi_{S 1 S 2}^{V W}$ & Total supplier cluster profit of case VW \\
\hline$\Pi_{S 1 S 2}^{V W C B}$ & Total supplier cluster profit of case VWCB \\
\hline$\Pi_{S 1 S 2}^{V W C C}$ & Total supplier cluster profit of case VWCC \\
\hline$\Pi_{S 1 S 2}^{V P C C}$ & Total supplier cluster profit of case VPCC \\
\hline$\Pi_{S 1 S 2}^{V P C B}$ & Total supplier cluster profit of case VPCB \\
\hline
\end{tabular}




\section{Assumption 4}

Market demand function of the product is given by $p=A-q_{s i}-q_{s j}$, where $q_{s i}$, $q_{s j}$ denotes the product output of supplier $i$ and $j$.

We will consider three supply chain stages. In Case VP, the buyer gives each supplier innovation request in the first stage, which is subject to spillover. In the second stage, each supplier competes in quantities as Cournot or Stackelberg oligopolists. In the final stage, the overseas buyer offers a a wholesale price according to consumer market demand function and output quantities of two suppliers. In Case VW, the innovation decisions are made by suppliers themselves. Therefore, in the first stage, two suppliers compete in quantities as Cournot or Stackelberg oligopolists. In the second stage, suppliers make innovation decisions according to product quantity scale. Here we assume the innovation decisions are made after production ones because suppliers in developing countries are mostly small in scale, therefore for them local competition and survival is prior than long-term development. In the final stage, the overseas buyer gives a wholesale price according to consumer market demand function and output quantities of two suppliers.

\section{Assumption 5}

The profit of the overseas buyer is given by:

$$
\Pi_{O B}=(p-w)\left(q_{s i}+q_{s j}\right),
$$

where $w$ represents the wholesale price offered by the buyer to suppliers. We utilize the wholesale price contract to describe the interaction because it is most commonly used in practice. We assume that the buyer applies a rule of thumb and always keeps the wholesale price as a proportion of final selling price in the consumer market as:

\section{Assumption 6}

$$
w=A_{1}-q_{s i}-q_{s j}, A_{1} / A=\lambda \text {. }
$$

The profit of the two suppliers is determined by:

$$
\begin{aligned}
& \Pi_{s i}=\left(w-\left(a-x_{s i}-b x_{s j}\right)\right) q_{s i}-\theta x_{s i}^{2} ; \\
& \Pi_{s j}=\left(w-\left(a-x_{s j}-b x_{s i}\right)\right) q_{s j}-\theta x_{s j}^{2},
\end{aligned}
$$

where $\theta x_{s i}^{2}$ and $\theta x_{s j}^{2}$ are the innovation expenditure to achieve the innovation output $x_{s i}, x_{s j}$. The coefficient $\theta$ denotes the magnitude of innovation cost. We define the innovation cost as increasing and convex in $x_{s i}, x_{s j}$, as typical in innovation research.

The supply chain innovation models in the next section involve different combinations of global and local power dynamics among players, characterized by the profit functions above.

\section{Supplier innovation models}

We will examine four supply chain innovation models with different combinations of global and local power dynamics are investigated as: (1) Case VPCB: vertical powerful buyer, cluster of balanced supplier power; (2) Case VWCB: vertical weak buyer, cluster of balanced supplier power; (3) Case VPCC: vertical powerful buyer, cluster of concentrated supplier power; (4) Case VWCC: vertical weak buyer, cluster of concentrated supplier power, Figure 1 illustrates the structures and power dynamics of the four supply chain innovation cases. 
a) Case VPCB

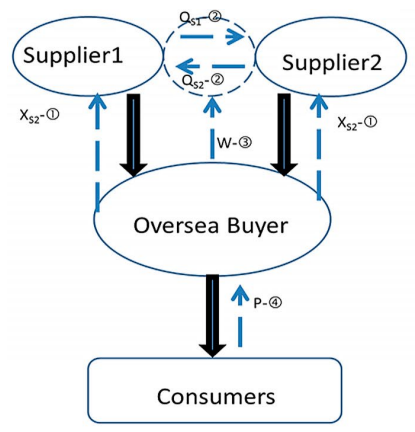

c) Case VWCB

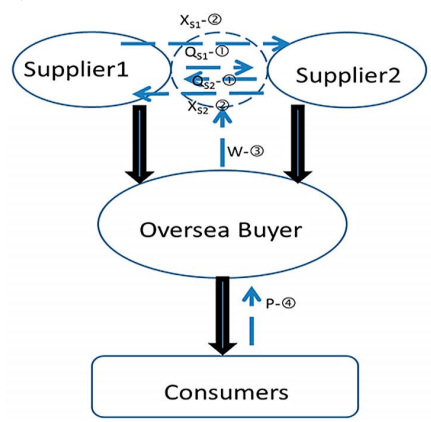

b) Case VPCC

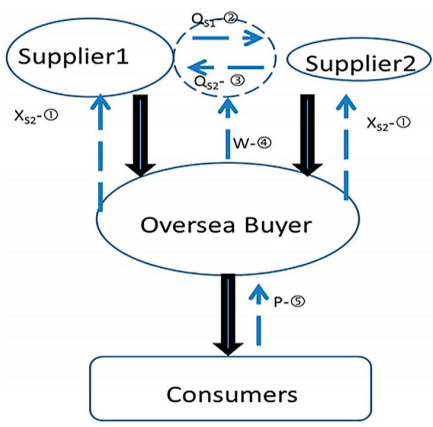

d) Case VWCC

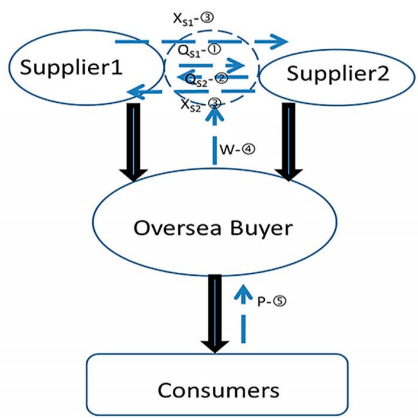

Figure 1. Supplier innovation models (X: innovation; Q: product quantity; W: wholesale price; P: retail price; solid line: product flow; dotted line: information flow)

\subsection{Case VPCB: vertical powerful buyer, cluster of balanced supplier power}

Case VPCB deals with a global supply chain consisting of a powerful overseas buyer who has cost-reducing innovation demand for its suppliers, and a cluster of two identical local suppliers who has balanced market power. It describes the situation in the early stage of suppliers' embedding in global supply chain. The powerful overseas buyer gives innovation output demand at the first stage of the game to maximize its profit. In the second stage, two local suppliers compete in quantities as Cournot oligopolists. In the final stage, the overseas buyer gives a wholesale price according to consumer market demand function and output quantities of two suppliers. The three-stage decision structure of Case VPCB can then be defined as follows:

$$
\begin{aligned}
& \text { Maximize } \Pi_{O B}\left(x_{s 1}, x_{s 2}\right) ; \\
& \text { Subject to } \Pi_{s 1}\left(q_{s 1} \mid x_{s 1}\right) \geq 0 ; \Pi_{s 2}\left(q_{s 2} \mid x_{s 2}\right) \geq 0 ; \\
& \text { Maximize } \Pi_{s 1}\left(q_{s 1} \mid x_{s 1}, x_{s 2}\right) ; \\
& \text { Maximize } \Pi_{s 2}\left(q_{s 2} \mid x_{s 1}, x_{s 2}\right) ; \\
& \text { Subject to } w=A_{1}-q_{s 1}-q_{s 2} ; \\
& \qquad p=A-q_{s 1}-q_{s 2} .
\end{aligned}
$$


The overseas buyer choose suppliers' innovation output to maximize its own profit in (5), but needs to satisfy constraints (6)-(10). Inequity (6) reflects the buyer's powerful position in that it includes not only the case when suppliers gain positive profit but also when they earn zero profit. This means we assume the powerful buyer is not worried about losing the supplier for the buyer is in a constant search of more competitive suppliers with lower costs. This coincides with theories in supply chain literatures that a powerful overseas buyer often has adversarial posture against its weak power suppliers instead of maintaining a persistent solid relationship (Kim et al., 2015). Constraint (7) and (8) state the process of simultaneous quantity competition among two local suppliers as Cournot oligopolists given the innovation demand of $x_{s 1}, x_{s 2}$. Constraint (9) and (10) describe how a unit wholesale price (offered by overseas buyer to local suppliers) and retail price of the product (offered by consumers to overseas buyer) are determined. The entire game process is a complete information dynamic game, and the equilibrium is a sub-game refined Nash equilibrium. Therefore, we obtain solutions through backward induction as in Appendix.

Proposition 1: In case VPCB, the game achieves an equilibrium on condition that $\theta>\frac{1}{9}\left(4-4 b+b^{2}\right)$, In equilibrium, the overseas buyer's profit is $2\left(-A+A_{1}\right)\left(3 A_{1} \theta-3 \alpha \theta+(1+\beta) \sqrt{\left(A_{1}-\alpha\right)^{2} \theta}\right)$

ter is $\frac{2\left(A_{1}(-1-\beta)+\alpha(1+\beta)-3 \sqrt{\left(A_{1}-\alpha\right)^{2} \theta}\right)}{1+2 \beta+\beta^{2}-9 \theta}$, total innovation output in the suppliers clus-

Proposition 1 shows that Case VP leads to an unreasonable distribution of value leaving suppliers earing zero profit. This is due to the extreme behavior of profit maximization by the powerful overseas buyer. When the overseas buyer has power over suppliers, it'll be only reasonable for it to take full advantage of that power since suppliers are passively embedded in the global supply chain without exit option, at least in the short run. It will cause an unreasonable distribution of value with embedded suppliers earning zero profits. GVC scholars have also argued that firms often fail to capture the value they created through upgrading under certain circumstances (Schrank, 2004; Mahutga, 2014; Sako \& Zylberberg, 2017). Chinese Suppliers of Sweden IKEA furniture are urged for cost-reducing innovations to reduce unit price by $2-3 \%$ every year, but the profits of suppliers are reported within a small profit margin for years. Some of the suppliers even suffered dismal operation and negative profit in the context of rising raw material and labor costs since 2010.

\subsection{Case VWCB: vertical weak buyer, cluster of balanced supplier power}

Case VWCB also considers a cluster of two identical local suppliers who has balanced market power, but the overseas buyer now has relatively weak power, meaning it leaves innovation decision to suppliers themselves. Therefore, in the first stage of the game, two suppliers compete in quantities as Cournot oligopolists. In the second stage, two suppliers simultaneously make their innovation decision to maximize their profit based on the quantity information. In the final stage, the overseas buyer offers a wholesale price according to consumer market 
demand function and output quantities of two suppliers. The three-stage decision structure of Case VWCB can then be defined as follows:

$$
\begin{aligned}
& \text { Maximize } \Pi_{s 1}\left(q_{s 1}\right) ; \\
& \text { Maximize } \Pi_{s 2}\left(q_{s 2}\right) ; \\
& \text { Subject to: } \text { Maximize } \Pi_{s 1}\left(x_{s 1} \mid q_{s 1}, q_{s 2}\right) ; \\
& \text { Maximize } \Pi_{s 2}\left(x_{s 2} \mid q_{s 1}, q_{s 2}\right) ; \\
& \text { Subject to } w=A_{1}-q_{s 1}-q_{s 2} ; \\
& \qquad p=A-q_{s 1}-q_{s 2} .
\end{aligned}
$$

In (11)-(12), two local suppliers compete in quantity as Cournot oligopolists to maximize its own profit, on condition of constraints (13)-(16). Constraint (13)-(14) reflects the process of suppliers making innovation decision given $q_{s 1}, q_{s 2}$. Constraint (15) and (16) represent how a unit wholesale price (offered by overseas buyer to local suppliers) and retail price of the product (offered by consumers to overseas buyer) are determined.

Proposition 2: In case VWCB, the game achieves an equilibrium on condition that $\theta>\frac{1}{4}$. In equilibrium, the overseas buyer's profit is $\frac{4\left(-A+A_{1}\right)\left(A_{1}-\alpha\right) \theta}{-1-\beta+6 \theta}$, total innovation output in the suppliers cluster is $\frac{2\left(A_{1}-\alpha\right)}{-1-\beta+6 \theta}$, total profit of the cluster is $\frac{2\left(A_{1}-\alpha\right)^{2} \theta(-1+4 \theta)}{(1+\beta-6 \theta)^{2}}$.

\subsection{Case VPCC: vertical powerful buyer, cluster of concentrated supplier power}

Case VPCC represents a global supply chain in which both vertical and horizontal market power structures are not balanced. Vertically, the overseas buyer is powerful in market force and gives direct innovation demand to its suppliers. Horizontally, one lead supplier has more market power and competes with others in quantity as a stackelberg oligopolist. This describes the situation in middle stage of suppliers' embeddness in global supply chain. In the first stage of the game, the oversea buyer gives direct innovation output demand to maximize its profit. In the second stage, two suppliers compete in quantity while the focal supplier acts as the Stackelberg oligopolist. In the final stage, the overseas buyer gives a wholesale price according to consumer market demand function and output quantities of two suppliers. The three-stage decision structure of Case VPCC can then be defined as follows:

$$
\begin{aligned}
& \text { Maximize } \Pi_{O B}\left(x_{s 1}, x_{s 2}\right) ; \\
& \text { Subject to } \Pi_{s 1}\left(q_{s 1} \mid x_{s 1}\right) \geq 0 ; \Pi_{s 2}\left(q_{s 2} \mid x_{s 2}\right) \geq 0 ; \\
& \text { Maximize } \Pi_{s 1}\left(q_{s 1} \mid x_{s 1}, x_{s 2}\right) ; \\
& \text { Subject to Maximize } \Pi_{s 2}\left(q_{s 2} \mid x_{s 1}, x_{s 2}, q_{s 1}\right) ; \\
& \text { Subject to } w=A_{1}-q_{s 1}-q_{s 2} ; \\
& p=A-q_{s 1}-q_{s 2} .
\end{aligned}
$$

The oversea buyer gives direct innovation output demand in (17) to maximize its profit on condition of (18)-(22). In (19)-(20), two local suppliers compete in quantity as one focal firm $s 1$ play the role of a Stackelberg leader. Constraint (21) and (22) represents how a unit wholesale price (offered by overseas buyer to local suppliers) and retail price of the product (offered by consumers to overseas buyer) are determined. 
Proposition 3: In case VPCC, the game achieves an equilibrium on condition that $0 \leq \beta<\frac{1}{2}(2-\sqrt{2})$ and $\theta>\frac{1}{16}\left(9-12 \beta+4 \beta^{2}\right) ;$ or $\frac{1}{2}(2-\sqrt{2})<\beta \leq 1$ and $\theta>\frac{1}{8}\left(4-4 \beta+\beta^{2}\right)$ In equilibrium, the overseas buyer's profit is $\frac{1}{4}\left(A-A_{1}\right)\left(3 A_{1}+x_{s 2}-3 \alpha+2 x_{s 2} \beta+x_{s 1}(2+\beta)\right)$, equilibriem innovation outputs are reached when both suppliers earns zero profit.

Unsurprisingly, Proposition 3 implies again that suppliers are not able to capture the value it created from innovation when it is embedded in a global supply chain with a vertical powerful buyer. As Tokatli also argued, "simply entering into a higher value-add activity does not guarantee the capture of additional value" (Tokatli, 2013).

\subsection{Case VWCC: vertical weak buyer, cluster of concentrated supplier power}

Case VWCC can be regarded as a situation in which local suppliers maintain more market power. Vertically, the overseas buyer is relatively weak and leaves innovation to suppliers' own decision. Horizontally, a lead (focal) firm competes in quantity with the other supplier as Stackelberg leaders. This illustrates the situation in mature stage of suppliers' embeddness in global supply chain. In the first stage of the game, the focal supplier competes in quantities with other supplier as Stackelberg oligopolist. In the second stage, two suppliers simultaneously make their innovation decision to maximize their profit based on the quantity information. In the final stage, the overseas buyer gives a wholesale price according to consumer market demand function and output quantities of two suppliers. The three-stage decision structure of Case VWCC can then be defined as follows:

Maximize $\Pi_{s 1}\left(q_{s 1}\right)$;

Subject to Maximize $\Pi_{s 2}\left(q_{s 2} \mid q_{s 1}\right)$;

Subject to Maximize $\Pi_{s 1}\left(x_{s 1} \mid q_{s 1}, q_{s 2}\right)$;

Maximize $\Pi_{s 2}\left(x_{s 2} \mid q_{s 1}, q_{s 2}\right)$;

Subject to $w=A_{1}-q_{s 1}-q_{s 2}$;

$$
p=A-q_{s 1}-q_{s 2} \text {. }
$$

In (23)-(24), two local suppliers compete in quantity as one focal firm play the role of a Stackelberg leader. Constraint (25)-(26) describe how they simultaneously make innovation decision to maximize their profit given $q_{s 1}, q_{s 2}$. Constraint (27) and (28) represents how a unit wholesale price (offered by overseas buyer to local suppliers) and retail price of the product (offered by consumers to overseas buyer) are determined.

Proposition 4: In case VWCC, the game achieves an equilibrium on condition that $\theta>\frac{1-\beta}{2}+\frac{\sqrt{1-4 \beta+4 \beta^{2}}}{2 \sqrt{2}}$. In equilibrium, the overseas buyer's profit is $\frac{2\left(A-A_{1}\right)\left(A_{1}-\alpha\right) \theta\left(2-2 \beta-\beta^{2}-12 \theta+12 \beta \theta+12 \theta^{2}\right)}{(-1+4 \theta)\left(1-2 \beta^{2}-8 \theta+8 \beta \theta+8 \theta^{2}\right)}$, total innovation output in the suppliers cluster is $\frac{\left(A_{1}-\alpha\right)\left(2-2 \beta-\beta^{2}-12 \theta+12 \beta \theta+12 \theta^{2}\right)}{(-1+4 \theta)\left(1-2 \beta^{2}-8 \theta+8 \beta \theta+8 \theta^{2}\right)}$, total profit of the cluster is 


$$
\begin{aligned}
& \frac{\theta\left(A_{1}-\alpha\right)^{2}}{(4 \theta-1)\left(1-2 \beta^{2}-8 \theta+8 \beta \theta+8 \theta^{2}\right)^{2}}\left(-2+\beta^{4}+24 \theta-88 \theta^{2}\right. \\
& +112 \theta^{3}-48 \theta^{4}+2 \beta^{3}(-3+8 \theta)+\beta^{2}\left(2+20 \theta-88 \theta^{2}\right)-4 \beta \\
& \left.\left(-1+14 \theta-46 \theta^{2}+32 \theta^{3}\right)\right)
\end{aligned}
$$

\section{Comparison of innovation models}

This section reveals how the above 4 innovation models with different global and local power dynamics differentiate in producing total innovation output and profit in the cluster.

\subsection{Total innovation output in the supply cluster}

Proposition 5: Under condition:
(a) $0 \leq \beta<\frac{1}{2}(2-\sqrt{2})$ or $\frac{1}{2}(2-\sqrt{2})<\beta<-2 \sqrt{2}+\sqrt{2(4+\sqrt{2})}$;
or $2 \sqrt{2}-\sqrt{2(4-\sqrt{2})}<\beta \leq 1$, with $\theta>\frac{1-\beta}{2}+\frac{\sqrt{1-4 \beta+4 \beta^{2}}}{2 \sqrt{2}}$.
(b) $\sqrt{2}(-2+\sqrt{4+\sqrt{2}})<\beta<-\sqrt{2}(-2+\sqrt{4-\sqrt{2}})$ with $\theta>\frac{1}{8}\left(4-4 \beta+\beta^{2}\right)$,

the following properties hold:

(1) $X_{S 1 S 2}^{V P}>X_{S 1 S 2}^{V W}$;

(2) $X_{S 1 S 2}^{V W C C}>X_{S 1 S 2}^{V W C B}$.

Proposition 5 implies that global supply chain relationship is the primary factor to determine innovation output. Total innovation output in Cases VP is always larger than in Cases VW. In Cases VP, the overseas buyer has power over local supplies and would maximize its profit by requesting innovation from suppliers to reduce unit cost, thus lead to greater innovation level. In Cases VW, the overseas buyer is not powerful and would leave the innovation choice to the suppliers' decision; total innovation in the cluster is less because suppliers often hold conservative and short-sighted attitude due to concerns on horizontal innovation spillover.

To illustrate the relative size of innovation of the four models more clearly, we choose parameters values within the set described in Proposition 5 as: $\mathrm{A} 1=1000, \mathrm{~A}=1100, \alpha=50$, $\beta=0.1 \sim 1, \theta=0.9$ for numerical simulation and obtain the result in Figure 2.

Proposition 6: Total innovation in the cluster follows: (1) $X_{S 1 S 2}^{V P C C}>X_{S 1 S 2}^{V P C B}>X_{S 1 S 2}^{V W C C}>X_{S 1 S 2}^{V W C B}$ when innovation spillover is sufficiently low; and (2) $X_{S 1 S 2}^{V P C B}>X_{S 1 S 2}^{V P C C}>X_{S 1 S 2}^{V W C C}>X_{S 1 S 2}^{V W C B}$ when innovation spillover is sufficiently high.

Proposition 6 indicates that Local competition structure plays its secondary role on cluster innovation through interaction with vertical chain relationship. In Cases VP, the relative size of innovation output in Case VPCB and VPCC differs with the degree of innovation spillover. When innovation spillover is sufficiently low, Case VPCC produces larger innovation output; when innovation spillover exceeds a threshold and continues to increase, Case VPCB produces larger innovation output, meanwhile the gap between the two widen as 


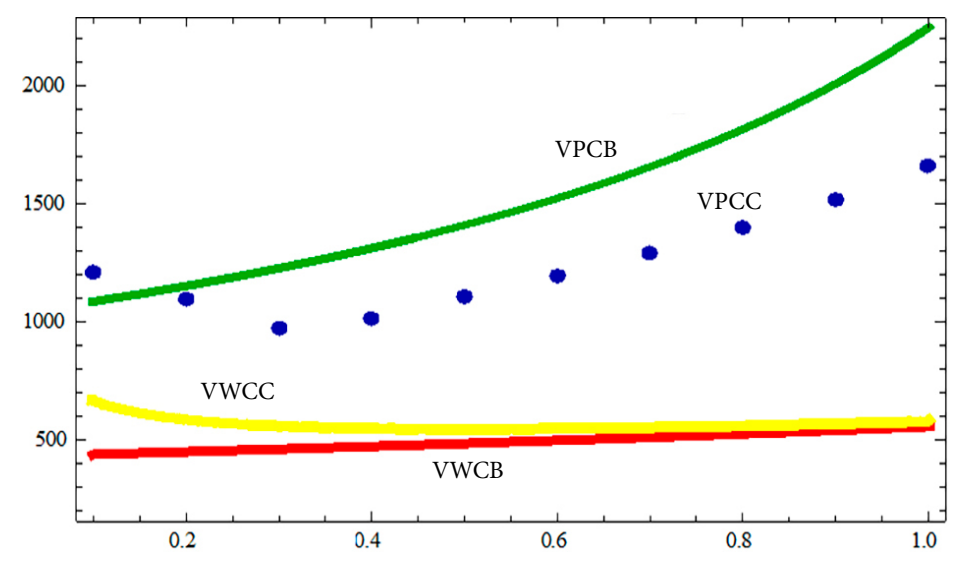

Figure 2. Comparison of cluster innovation

innovation spillover increases. This is due to the fact that, when innovation spillover is low, supplier's main innovation consideration is their capital capability; VPCC's lead supplier has stronger capital strength which leads to larger innovation. As innovation spillover increases, the lead supplier starts to reduce its innovation to prevent spillover. In contrast, two suppliers in Case VPCB both benefit from spillover and increase their innovation until total innovation output of VPCB surpass VPCC at the spillover thresholds and continue to increase. In Cases VW, VWCC always produces larger innovation output than Case VWCB, but the gap between the two tends to converge. This is because when the overseas buyer is not powerful, the lead supplier is more capable in obtaining profit from its innovation, thus do not reduce its innovation much with increase of spillover. However, since the two suppliers in VWCB both benefit while the lead firm in VWCC loss from spillover, the gap between the two tends to converge with the increase of spillover. This is consistent to GVC research which underlines the importance of the hub-and-spoke form in upgrading but also shows that it is neither a necessary nor a sufficient condition for upgrading (Knorringa, 1996).

Proposition 7: an increase in innovation spillover:

(1) increases total innovation in the cluster under cases VPCB and VWCB;

(2) first reduces and then increases total innovation in the cluster passing the threshold point under cases VPCC;

(3) reduces total innovation in the cluster under VWCC.

Proposition 7 implies that in Cases CB, increased innovation spillover will always lead to higher total innovation output in the cluster. This is due to the fact that the two suppliers in Case CB both benefit from innovation spillover and will increase their innovation following spillover increase. In Cases CC, the situation is more complex. In Case VWCC, the lead supplier will reduce its innovation gradually with increase of spillover. In Case VPCC, at early stage of spillover, the lead firm will reduce its innovation till the overseas buyer intervenes at the threshold, and turn to increase its innovation afterwards to avoid upsetting their relationship. 


\subsection{Total profit of supply clusters}

Proposition 8: Under condition (a) $0 \leq \beta<\frac{1}{2}(2-\sqrt{2})$ or $\frac{1}{2}(2-\sqrt{2})<\beta<-2 \sqrt{2}+\sqrt{2(4+\sqrt{2})}$ or $2 \sqrt{2}-\sqrt{2(4-\sqrt{2})}<\beta \leq 1$, with $\theta>\frac{1-\beta}{2}+\frac{\sqrt{1-4 \beta+4 \beta^{2}}}{2 \sqrt{2}}$; or $($ b) $\sqrt{2}(-2+\sqrt{4+\sqrt{2}})<\beta<$ $-\sqrt{2}(-2+\sqrt{4-\sqrt{2}})$ with $\theta>\frac{1}{8}\left(4-4 \beta+\beta^{2}\right)$, property $\Pi_{S 1 S 2}^{V P}<\Pi_{S 1 S 2}^{V W}$ holds.

From Proposition 1 and 3, we can see that in the case of a vertically strong buyer, the profit of each supplier is zero. In the case of vertically weak buyers, the profit of each supplier is greater than zero. Therefore, the total profit of the local supply cluster in the case of weak vertical buyers is higher than that in the case of strong vertical buyers.

As previously discussed, in Cases VP, powerful overseas buyers' profit maximizing will lead to zero profit for local suppliers. Therefore, although Cases VP produce larger innovation, it should be noted that the situation is unsustainable.

Again we choose parameters within the set described in Proposition 8 and let A1 $=1000$, $\mathrm{A}=1100, \alpha=50, \beta=0.1 \sim 1, \theta=0.9$, then we conduct numerical simulation and obtain the results shown in Figure 3.

Proposition 9: Total profit in the cluster follows: (1) $\Pi_{S 1 S 2}^{V W C C}>\Pi_{S 1 S 2}^{V W C B}>\Pi_{S 1 S 2}^{V P C C}=\Pi_{S 1 S 2}^{V P C B}$ when innovation spillover is sufficiently low; and (2) $\Pi_{S 1 S 2}^{V W C B}>\Pi_{S 1 S 2}^{V W C C}>\Pi_{S 1 S 2}^{V P C C}=\Pi_{S 1 S 2}^{V P C B}$ when innovation spillover is sufficiently high.

Proposition 10: In Case VWCB, the total profit of the supply cluster is positively correlated with the innovation spillover; In Case VWCC, the correlation between total profit of the supply cluster and innovation spillover changes from negative to positive at the spillover threshold.

Propositions 9 and 10 show the effect of spillover on total profit of the cluster. In the early stage of spillover, Case VWCC produces higher total profit in the cluster than VWCB. However, with the increase of innovation spillover, total profit of VWCB surpasses VWCC though the gap between the two tends to converge. This is because at the early stage, the

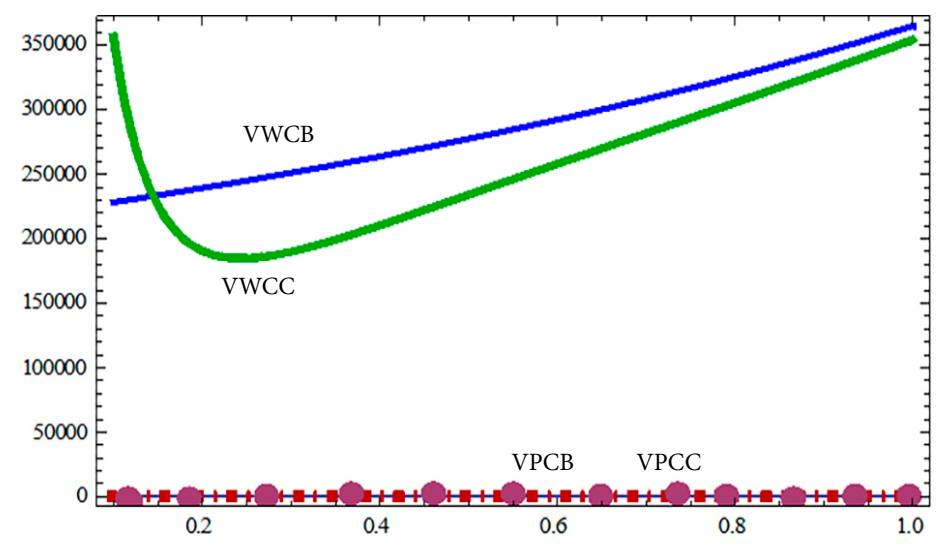

Figure 3. Comparison of cluster profit 
lead supplier who has capital strength for innovation constitute the main part of total profit and brings a relative higher total profit in Case VWCC. With the increase of spillover, the suppliers in VWCB benefit from spillover and cause the total profit to slowly catches up and then surpass CWCC at the threshold.

GVC scholars' empirical study also supports that spillover plays an important role in profiting from innovation. As Schrank noted, suppliers' returns to upgrading in Dominican Republic diminish because it's easy to imitate the innovation practice (Schrank, 2004).

We also choose other parameter combinations that meet the conditions in Proposition 5 and 8 , the conclusions are consistent with Propositions 5-10. In addition, the threshold value of innovation spillover parameter under each parameter combination are found to be similarly small around 0.2 , therefore, we particularly consider the situation passing the threshold which are common cases in practice and obtain the result in Figure 4 through direct comparison.

It is obvious that although cases VP produce larger innovation, they both cause zero profits in the supply cluster. This result is consistent with prior supply chain relationship and GVC studies. As some scholars argued that sticky relationships lead to poor performance for suppliers (Kim et al., 2015; Revilla \& Villena, 2012; Swink \& Zsidisin, 2006) and successful upgrading does not necessarily correspond with greater value capture (Gereffi, 2019). In practice, when overseas buyers have strong market power over suppliers, they often give local suppliers pressure on innovation to reduce unit cost while capture most of the values created in the chain. For example, most of the Chinese suppliers of Swedish IKEA furniture complained about pressure from the buyer on innovation to reduce unit cost. Although they did improve their technology, their profits are controlled in the marginal space and dismal operations and losses often occur. This illustrates the reality that innovations driven by powerful overseas buyers are not profitable and thus not sustainable. Local suppliers need to reevaluate the chain relationship and de-embed when necessary. In 2013, ten IKEA suppliers in China broke away from IKEA's supply relationship; similar cases also happened in 2012 when 10 Chinese suppliers terminated their cooperation with Adidas. The dark side of embedding in

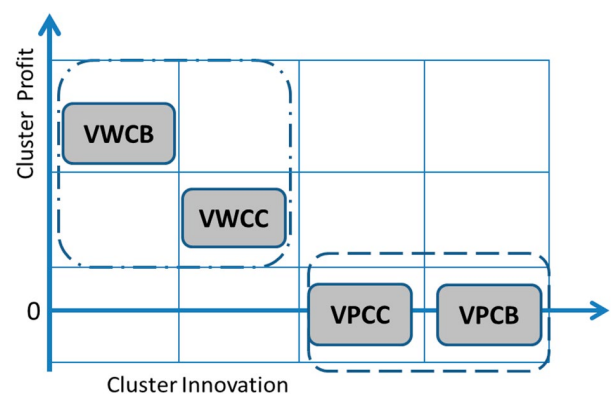

Figure 4. Comparison of cluster innovation under high spillover a chain with powerful buyers is recognized by suppliers gradually. In knitwear cluster in Ludhiana, India, some of the leading knitwear suppliers prefer to work with the small foreign buyers, rather than the large ones, because these relationships are more symmetrical and give them the space for their own innovation (Humphrey \& Schmitz, 2000). Taken together, only when local suppliers develop enough and overseas buyers do not have excess power over them, could the suppliers benefit from their innovation. 


\section{Managerial implications}

Our study offers important insights for managerial practice and more broadly for territorial economic development. These insights follow directly from the propositions put forth in this article, as shown in Table 5. First, supply chain managers do not have to view embeddedness as a one-time choice. Rather, they can revise the embeddedness of the global supply chain relationship dynamically. Our study notably shows how closely embeddness in a chain with powerful overseas buyer could lead to zero profit. Firms can de-embed by diversifying business across multiple overseas buyers and consumers through e-commerce. As Sako and Zylberberg (2017) also showed, structuring its buyer portfolio is one important strategy for suppliers to profit from its innovation. However, re-embedding in the cognitive dimension can be particularly difficult. It encompasses developing new capabilities in new market and risk management, and suppliers in the clusters are often short-sighted to enjoy the (considerable) short-term benefits. Therefore, realignment may not be straightforward.

Second, our comparisons of innovation under different regime also shed light to local industry policy making. In case of low spillover due to strong regimes of appropriability or low information flow, concentrated competition is likely to produce more cluster innovation, therefore government policy should favor to supporting mortgage and lead firms' grow. In the opposite case of weak legal appropriability regimes or high spillover, policy should focus more on balancing market power and enhancing industry associations when overseas buyer is powerful, but supporting lead firms when overseas buyer is not powerful. Yet, it should be noted that impropriate interfering in competition structure might leads to market chaos, which in turn can hurt supply cluster's development.

Third, our investigation of the role of spillover informs that, innovation increase with spillover under balanced power market structures. Intuition calls for more coordination between suppliers at the early stage of embeddness in global supply chain when firms have rela-

Table 5. Linking propositions with managerial implications (source: author's summary)

\begin{tabular}{|l|l|}
\hline \multicolumn{1}{|c|}{ Theoretical finding (propositions) } & \multicolumn{1}{c|}{ Managerial implication } \\
\hline $\begin{array}{l}\text { Under case VPCB and VPCC, suppliers } \\
\text { earns zero profit (Proposition 1,3) }\end{array}$ & $\begin{array}{l}\text { Managers do not have to view GVC embeddedness as } \\
\text { a one-time choice, instead, de-embedding should be } \\
\text { considered when profit margin is low }\end{array}$ \\
\hline $\begin{array}{l}\text { Cluster innovation varies with spillover: } \\
X_{S 1 S 2}^{V P C C}>X_{S 1 S 2}^{V P C B}>X_{S 1 S 2}^{V W C C}>X_{S 1 S 2}^{V W C B}, \\
\text { with low spillover: } \\
X_{S 1 S 2}^{V P C B}>X_{S 1 S 2}^{V P C C}>X_{S 1 S 2}^{V W C C}>X_{S 1 S 2}^{V W C B}, \\
\text { with high spillover (Proposition 6) }\end{array}$ & $\begin{array}{l}\text { Marketing structure policy (if necessary) should be } \\
\text { made with prudent consideration of global supply chain } \\
\text { relationship and spillover situation }\end{array}$ \\
\hline $\begin{array}{l}\text { Under Case CB, innovation increase } \\
\text { with spillover (Proposition 7) }\end{array}$ & $\begin{array}{l}\text { At the early stage of embeddness in global supply chain } \\
\text { with balanced power suppliers, supporting local policy } \\
\text { should focus on the role of industry associations }\end{array}$ \\
\hline $\begin{array}{l}\text { Cluster profit follows: } \Pi_{S 1 S 2}^{V W}>\Pi_{S 1 S 2}^{V P} \\
\text { (Proposition 9) }\end{array}$ & $\begin{array}{l}\text { Local government should be aware that supporting } \\
\text { suppliers converting from embeddedness in a global supply } \\
\text { chain with powerful buyer to more balanced relationship is } \\
\text { necessary for sustainable development in the cluster }\end{array}$ \\
\hline
\end{tabular}


tively balanced power over each other. Local supporting policies should thus be emphasized more on promoting industry associations at the beginning of embeddness.

Fourth, our comparison of cluster profit notably shows that embeddness in a global supply chain with powerful buyer is not a sustainable path for local industry development. As Humphrey noted, "Power is relational: the exercise of power by one party depends on the powerlessness of other parties in the chain" (Humphrey \& Schmitz, 2000). It is important for local government to recognize the limit of buyer-driven upgrading and innovation. Since suppliers in developing economy often lack capacity strength to invest in innovation, it seems reasonable to assume that the sustainable development of the cluster would depend heavily on local and national systems of innovation support.

\section{Conclusions}

Embedding in global supply chain has helped local suppliers improve their technology, but it is also noted in recent years that the innovation and upgrading driven by overseas buyers are not sustainable. When a local government forms its industry policy, it becomes of great importance in practice to understand the effect of both vertical global chain and horizontal local competition power dynamics. To the best of our knowledge, this study is the first to investigate these issues. Thus, this study contributes to the literature by bridging the gap between practice and academia, while providing valuable practical insights to local suppliers.

In this study, cluster suppliers' innovation is investigated in a global and local superposed context, consisting of an overseas buyer, competing local suppliers and consuming market. Four different types of cluster innovation models, differing in global and local power dynamics, are introduced. The comparison of their innovation and profit performance provides important implications. These can be summarized as follows. First, global supply chain relationship is the primary factor to influence local cluster innovation and profit. Total innovation of the cluster is proved to be greater in global supply relationship with a powerful buyer than with a non-powerful buyer. However, suppliers in a powerful buyer chain are not able to capture the value they created as usually expected. Total profit is always higher in cases with a non-powerful overseas buyer than with powerful overseas buyer regardless of local competition structure. Second, local competition structure play its secondary role on cluster innovation through interaction with the vertical chain relationship. The relationship between power dynamic interaction and cluster innovation is also adjusted by the innovation spillover. Overall, it can be concluded that suppliers cluster's innovation is dynamically and complexly determined by global supply chain relationship, local market competition, and innovation spillover as well. Supplier managers should bear in mind that innovation doesn't inherently equal profit. Local industry policy needs to be made cautiously with considerations of both global and local market power dynamics.

Our study can be generalized in analyzing supplier innovation under global and local context and has important implications for research and practice. However, limitation exists due to its limiting assumptions. First, we have assumed that local suppliers are not able to de-embed from the chain at least in short run due to sink cost of specific investment. Although this was the case for a long time, the recent rapid development of global e-commerce 
has made it possible for suppliers to break the chain and directly sell to overseas customers. Therefore, it will be necessary to include the cases when supplier could make de-embedding decisions. Second, the supply chain relationship is assumed to be existing ones which cannot be altered by suppliers. However, as Sako and Zylberberg argued, under certain circumstances suppliers could change the supply chain polarity without de-embedding from it (Sako \& Zylberberg, 2017). Third, the suppliers are assumed to be not able to preventing innovation spillover. This assumption suits the case under weak appropriability regime of developing economy. But firms will sure be able to have more ways to invest in secrecy to limit innovation spillovers gradually. Fourth, innovation is characterized as incremental and cost-reducing in our study. We are aware that for a higher-level upgrading, cases of qualityimproving innovation, radical product and functional innovation need to be considered as well. Fifth, we investigated the role of inter-firm level dynamics on supplier innovation, noting that there exists a broad consistuency of actors who also have influence beyond the market arena. Relaxing the assumption and incorporating the above issues in a future study will allow the development of practical implications that better correspond to the current supplier innovation environment.

\section{Funding}

This work was supported by the Humanities and Social Science Research project of the Ministry of Education of China under Grant "Evolution of global supply network and reembedding of small and medium suppliers" [number 19YJA630013] and the general project of National Natural Science Foundation of China under Grant "Formation Mechanism of Enterprise Network Power, Its Allocation Efficiency and Influence on Cooperative Behavior" [number 71872014].

\section{Disclosure statement}

The authors declare no conflict of interests.

\section{References}

Amin, A., \& Thrift, N. (1992). Neo-Marshallian nodes in global networks. International Journal of Urban and Regional Research, 16(4), 571-587. https://doi.org/10.1111/j.1468-2427.1992.tb00197.x

Bellandi, M. (1996). Innovation and change in the Marshallian industrial district. European Planning Studies, 4(3), 357-368. https://doi.org/10.1080/09654319608720351

Coe, N. M., \& Yeung, H. W.-C. (2015). Global production networks: Theorizing economic development in an interconnected world. Oxford University Press. https://doi.org/10.1093/acprof:oso/9780198703907.001.0001

Dallas, M. P., Ponte, S., \& Sturgeon, T. J. (2019). Power in global value chains. Review of International Political Economy, 26(4), 666-694. https://doi.org/10.1080/09692290.2019.1608284

De Elejalde, R., Ponce, C., \& Roldán, F. (2019). Innovation and competition, and incentives: Evidence from Uruguayan firms (ILADES-UAH Working Papers inv328). Universidad Alberto Hurtado/ School of Economics and Business. 
De Propris, L., \& Lazzeretti, L. (2009). Measuring the decline of a Marshallian industrial district: The Birmingham jewellery quarter. Regional Studies, 43(9), 1135-1154.

https://doi.org/10.1080/00343400802070894

Dias, A. T., Rossi, F. S. M., Silva, J. T. M., de Camargos, M. A., \& de-Carvalho, J. P. (2020). The effects of competitive environment and strategic factors on US firm performance before and after the global financial crisis. Latin American Business Review, 21(1), 37-59. https://doi.org/10.1080/10978526.2019.1676648

Dong, S., \& Sun, Y. (2020). Upgrading path and value chain upgrading strategy of China's marine equipment manufacturing industry. Journal of Coastal Research, 107, 157-160. https://doi.org/10.2112/JCR-SI107-040.1

Ellram, L. M., \& Cooper, M. C. (1990). Supply chain management, partnership, and the shipper - third party relationship. The International Journal of Logistics Management, 1(2), 1-10. https://doi.org/10.1108/95740939080001276

Gereffi, G. (2019). Economic upgrading in global value chains. In Handbook on global value chains. Edward Elgar Publishing. https://doi.org/10.4337/9781788113779.00022

Gereffi, G., \& Kaplinsky, R. (2001). The value of value chains: spreading the gains from globalisation. Institute of Development Studies.

Gereffi, G., \& Korzeniewicz, M. (1994). Commodity chains and global capitalism. ABC-CLIO.

Giuliani, E., Pietrobelli, C., \& Rabellotti, R. (2005). Upgrading in global value chains: lessons from Latin American clusters. World Development, 33(4), 549-573. https://doi.org/10.1016/j.worlddev.2005.01.002

Gorzelany-Dziadkowiec, M., Gorzelany, J., Stauskis, G., Hernik, J., Van Assche, K., \& Noszczyk, T. (2019). The innovation process in local development - the material, institutional, and intellectual infrastructure shaping and shaped by innovation. Technological and Economic Development of Economy, 25(6), 1232-1258. https://doi.org/10.3846/tede.2019.11094

Hoegl, M., \& Wagner, S. M. (2005). Buyer-Supplier collaboration in product development projects. Journal of Management, 31(4), 530-548. https://doi.org/10.1177/0149206304272291

Humphrey, J., \& Schmitz, H. (2000). Governance and upgrading: linking industrial cluster and global value chain research (Vol. 120). Institute of Development Studies Brighton.

Humphrey, J., \& Schmitz, H. (2002). How does insertion in global value chains affect upgrading in industrial clusters? Regional Studies, 36(9), 1017-1027. https://doi.org/10.1080/0034340022000022198

International Labour Office. (2003). Employment and social policy in respect of export processing zones (EPZs) (GB. 286/ESP/3, 286th session). Geneva.

Jap, S. D. (1999). Pie-expansion efforts: Collaboration processes in buyer-supplier relationships. Journal of Marketing Research, 36(4), 461-475. https://doi.org/10.1177/002224379903600405

Jensen, M. B., Johnson, B., Lorenz, E., \& Lundvall, B. A. (2007). Forms of knowledge and modes of innovation. Research Policy, 36(5), 680-693. https://doi.org/10.1016/j.respol.2007.01.006

Jurowetzki, R., Lema, R., \& Lundvall, B. A. (2018). Combining innovation systems and global value chains for development: Towards a research agenda. European Journal of Development Research, 30(3), 364-388. https://doi.org/10.1057/s41287-018-0137-4

Kadarusman, Y., \& Nadvi, K. (2013). Competitiveness and technological upgrading in global value chains: Evidence from the indonesian electronics and garment sectors. European Planning Studies, 21(7), 1007-1028. https://doi.org/10.1080/09654313.2013.733850

Kaplinsky, R. (1993). Export processing zones in the Dominican Republic: Transforming manufactures into commodities. World Development, 21(11), 1851-1865.

https://doi.org/10.1016/0305-750X(93)90087-P 
Kaplinsky, R. (2000). Globalisation and unequalisation: What can be learned from value chain analysis? The Journal of Development Studies, 37(2), 117-146. https://doi.org/10.1080/713600071

Kim, Y., Choi, T. Y., \& Skilton P. F. (2015). Buyer-supplier embeddedness and patterns of innovation. International Journal of Operations \& Production Management, 35(3), 318-345. https://doi.org/10.1108/IJOPM-05-2013-0251

Kim, Y., \& Choi, T. Y. (2015). Deep, sticky, transient, and gracious: An expanded buyer-supplier relationship typology. Journal of Supply Chain Management, 51(3), 61-86. https://doi.org/10.1111/jscm.12081

Knorringa, P. (1996). Economics of collaboration: Indian shoemakers between market and hierarchy. Sage Publications.

Lee, C.-Y. (2005). A new perspective on industry R\&D and market structure. The Journal of Industrial Economics, 53(1), 101-122. https://doi.org/10.1111/j.0022-1821.2005.00247.x

Lundvall, B. A., Johnson, B., Andersen, E. S., \& Dalum, B. (2002). National systems of production, innovation and competence building. Research Policy, 31(2), 213-231. https://doi.org/10.1016/S0048-7333(01)00137-8

Markusen, A. (1996). Sticky places in slippery space: a typology of industrial districts. Economic Geography, 72(3), 293-313. https://doi.org/10.2307/144402

Odei, S. A., \& Stejskal, J. (2020). Firms pursuit of innovations through internationalization: A treatment effect estimation. Technological and Economic Development of Economy, 26(4), 837-866. https://doi.org/10.3846/tede.2020.12484

Pahl, S., \& Timmer, M. P. (2020). Do global value chains enhance economic upgrading? A long view. The Journal of Development Studies, 56(9), 1683-1705. https://doi.org/10.1080/00220388.2019.1702159

Porter, M. E. (1990). The competitive advantage of nations. Macmillan Press. https://doi.org/10.1007/978-1-349-11336-1

Raj-Reichert, G. (2020). Global value chains, contract manufacturers, and the middle-income trap: The electronics industry in Malaysia. The Journal of Development Studies, 56(4), 698-716. https://doi.org/10.1080/00220388.2019.1595599

Revilla, E., \& Villena, V. H. (2012). Knowledge integration taxonomy in buyer-supplier relationships: Trade-offs between efficiency and innovation. International Journal of Production Economics, 140(2), 854-864. https://doi.org/10.1016/j.ijpe.2012.07.002

Sabel, C. (1989). Flexible specialization and the re-emergence of regional economies. In P. Hirst, \& J. Zeitlin (Eds.), Reversing industrial decline. Berg Publishers Ltd.

Sako, M., \& Zylberberg, E. (2017). Supplier strategy in global value chains: Shaping governance and profiting from upgrading. Socio-Economic Review, 17(3), 687-707. https://doi.org/10.1093/ser/mwx049

Schmitz, H. (1992). Industrial districts: Model and reality in Baden-Württemberg, Germany. In Industrial districts and local economic regeneration (pp. 87-121). International Labour Organisation.

Schrank, A. (2004). Ready-to-wear development? Foreign investment, technology transfer, and learning by watching in the apparel trade. Social Forces, 83(1), 123-156. https://doi.org/10.1353/sof.2004.0126

Shapiro, C. (2011). Competition and innovation: did arrow hit the Bull's eye? In The rate and direction of inventive activity revisited (pp. 361-404). University of Chicago Press. https://doi.org/10.7208/chicago/9780226473062.003.0011

Sting, F. J., Stevens, M., \& Tarakci, M. (2019). Temporary deembedding buyer - supplier relationships: A complexity perspective. Journal of Operations Management, 65(2), 114-135.

https://doi.org/10.1002/joom.1008 
Swink, M., \& Zsidisin, G. (2006). On the benefits and risks of focused commitment to suppliers. International Journal of Production Research, 44(20), 4223-4240. https://doi.org/10.1080/00207540600575761

Tewari, M. (2008). Varieties of global integration: Navigating institutional legacies and global networks in India's garment industry. Competition \& Change, 12(1), 49-67. https://doi.org/10.1179/102452907X264520

Tokatli, N. (2013). Toward a better understanding of the apparel industry: A critique of the upgrading literature. Journal of Economic Geography, 13(6), 993-1011. https://doi.org/10.1093/jeg/lbs043

Villena, V. H., Choi, T. Y., \& Revilla, E. (2020). Mitigating mechanisms for the dark side of collaborative buyer-supplier relationships: A mixed-method study. Journal of Supply Chain Management, 1-31. https://doi.org/10.1111/jscm.12239

Wilson, D. T. (1995). An integrated model of buyer-seller relationships. Journal of the Academy of Marketing Science, 23(4), 335-345. https://doi.org/10.1177/009207039502300414

You, W., \& Virtanen, Y. (2020). Economic and social upgrading in an industrial cluster in GVCs. Academy of Management Proceedings, 2020(1), 16639. https://doi.org/10.5465/AMBPP.2020.16639abstract

Yu, M. C., Lu, Y. J., Li, C., Lin, H., \& Shapira, P. (2019). More is less? The curvilinear effects of political ties on corporate innovation performance. Technological and Economic Development of Economy, 25(6), 1309-1335. https://doi.org/10.3846/tede.2019.10718

Zaheer, A., McEvily, B., \& Perrone, V. (1998). The strategic value of buyer-supplier relationships. International Journal of Purchasing and Materials Management, 34(2), 20-26.

https://doi.org/10.1111/j.1745-493X.1998.tb00292.x

Zhu, S., \& He, C. (2018). Upgrading in China's apparel industry: international trade, local clusters and institutional contexts. Post-Communist Economies, 30(2), 193-215.

https://doi.org/10.1080/14631377.2017.1362099

\section{APPENDIX A}

\section{Proof of propositions}

Proof of Proposition 1. Through backward induction, we first apply (9) in (7) and (8), and obtain the second derivatives of $q_{s 1}, q_{s 2}$ in $\Pi_{s 1}$ and $\Pi_{s 2}$ as: $\frac{\partial^{2} \Pi_{s 1}}{\partial q_{s 1}{ }^{2}}=-2<0, \frac{\partial^{2} \Pi_{s 2}}{\partial q_{s 2}{ }^{2}}=-2<0$; therefore, $\Pi_{s 1}$ and $\Pi_{s 2}$ are concave functions about $q_{s 1}, q_{s 2}$. By partially differentiating $\Pi_{s 1}$ and $\Pi_{s 2}$ with respect to $q_{s 1}, q_{s 2}$, we obtain the first-order necessary conditions (FONCs). Simultaneously solving those FONCs yields:

$q_{S 1}=\frac{1}{3}\left(A_{1}-x_{s 2}-\alpha-x_{s 1}(-2+\beta)+2 x_{s 2} \beta\right), q_{S 2}=\frac{1}{3}\left(A_{1}+2 x_{s 2}-\alpha-x_{s 2} \beta+x_{s 1}(-1+2 \beta)\right)$.

Given the above equations, the Hessian determinants of $x_{s 1}, x_{s 2}$ in $\Pi_{O B}$ is $\left|\mathrm{H}_{2}\right|^{\Pi_{O B}}=0$. This doesn't satisfy the negative-definite property of the second order sufficient condition. Now we turn to the first order derivative of $x_{s 1}, x_{s 2}$ in $\Pi_{O B}$ as: $\frac{\partial \Pi_{O B}}{\partial x_{s 1}}=\frac{1}{3}\left(A-A_{1}\right)(1+\beta)>0$, $\frac{\partial \Pi_{O B}}{\partial x_{s 2}}=\frac{1}{3}\left(A-A_{1}\right)(1+\beta)>0$. Therefore, the overseas buyer would choose the larger corner solutions to maximize its profit, which means it will choose the largest value of $x_{s 1}, x_{s 2}$ on condition that suppliers' profits are non-negative. It is natural to assume that the sup- 
pliers' profit functions are concave in $x_{s 1}, x_{s 2}$, which requests $\frac{\partial^{2} \Pi_{s 1}}{\partial x_{s 1}{ }^{2}}<0$ and $\frac{\partial^{2} \Pi_{s 2}}{\partial x_{s 2}{ }^{2}}<0$ and yields $\theta>\frac{1}{9}\left(4-4 \beta+\beta^{2}\right)$. Given concavity condition, it is obvious that the optimal $x_{s 1}$, $x_{s 2}$ are the larger solutions when suppliers have zero profits. Then, we simultaneously solve $\Pi_{s 1}=0$ and $\Pi_{s 2}=0$, then compare the solutions and choose larger solutions to obtain: $x_{s 1}=x_{s 2}=\frac{-A_{1}+\alpha-A_{1} \beta+\alpha \beta-3 \sqrt{A_{1}^{2} \theta-2 A_{1} \alpha \theta+\alpha^{2} \theta}}{1+2 \beta+\beta^{2}-9 \theta}$. Through backward induction we get that total innovation output in the cluster is $\frac{2\left(A_{1}(-1-\beta)+\alpha(1+\beta)-3 \sqrt{\left(A_{1}-\alpha\right)^{2} \theta}\right)}{1+2 \beta+\beta^{2}-9 \theta}$, the

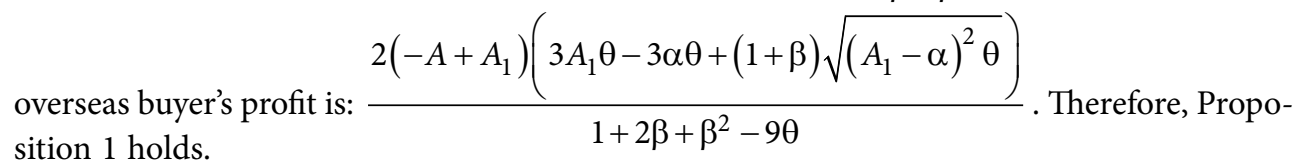

Proof of Proposition 2. Through similar approach as in 4.2, we can prove that given $\theta>\frac{1}{4}$, the concavity of profit functions in each stages can be satisfied and the game has equilibrium outcome. We then apply (15) into (13)-(14) and solve the FONC conditions about $x_{s 1}, x_{s 2}$ to obtain: $x_{s 1}=\frac{q_{s 1}}{2 \theta}, x_{s 2}=\frac{q_{s 2}}{2 \theta}$.

Substituting these equations into (11) and (12), and solving the FONC conditions about $q_{s 1}, q_{s 2}$ yields: $q_{s 1}=\frac{2\left(A_{1}-\alpha\right) \theta}{-1-\beta+6 \theta}, q_{s 2}=\frac{2\left(A_{1}-\alpha\right) \theta}{-1-\beta+6 \theta}$. Then we apply the value of $q_{s 1}, q_{s 2}$ to other variables through backward induction and obtain the value of our objective expressions. We get that the overseas buyer's profit is $\frac{4\left(-A+A_{1}\right)\left(A_{1}-\alpha\right) \theta}{-1-\beta+6 \theta}$, total innovation output in the suppliers cluster is $\frac{2\left(A_{1}-\alpha\right)}{-1-\beta+6 \theta}$, total profit of the cluster is $\frac{2\left(A_{1}-\alpha\right)^{2} \theta(-1+4 \theta)}{(1+\beta-6 \theta)^{2}}$ . Therefore, Proposition 2 holds.

Proof of Proposition 3. Substituting (21) into (19) and (20), we obtain the second derivative of $\Pi_{s 1}$ and $\Pi_{s 2}$ about $q_{s 1}, q_{s 2}$ as: $\frac{\partial^{2} \Pi_{s 1}}{\partial q_{s 1}{ }^{2}}=-2<0, \frac{\partial^{2} \Pi_{s 2}}{\partial q_{s 2}{ }^{2}}=-2<0$. Therefore, $\Pi_{s 1}$ and $\Pi_{s 2}$ are both concave with respective to $q_{s 1}, q_{s 2}$. We then solve the FONC equation of (20) and obtain: $q_{s 2}=-q_{s 1} \beta-2 w \theta+2 \alpha \theta$. Substituting this equation into (19) and solving the FONC equation of (19) yields: $q_{s 1}=-\frac{2(-w+\alpha+w \beta-\alpha \beta) \theta}{-1+2 \beta^{2}}$. Applying the above expression of $q_{s 1}, q_{s 2}$ into (17), we obtain the Hessian determinants of $x_{s 1}, x_{s 2}$ in $\Pi_{O B}$ as $\left|\mathrm{H}_{2}\right|^{\Pi_{O B}}=0$. This doesn't satisfy the negative-definite property of the second order sufficient condition. Now we turn to the first order derivative of $x_{s 1}, x_{s 2}$ in $\Pi_{O B}$ as this doesn't satisfy the negative-definite property of the second order sufficient condition and get: $\frac{\partial \Pi_{O B}}{\partial x_{s 1}}=\frac{1}{3}\left(A-A_{1}\right)(1+\beta)>0$, $\frac{\partial \Pi_{O B}}{\partial x_{s 2}}=\frac{1}{3}\left(A-A_{1}\right)(1+\beta)>0$. Therefore, the overseas buyer would choose the larger corner solutions to maximize its profit, which means it will choose the largest value of $x_{s 1}, x_{s 2}$ on 
condition that suppliers' profits are non-negative as in Case CPVB. Assuming the suppliers' profit functions are concave in $x_{s 1}, x_{s 2}$ as $\frac{\partial^{2} \Pi_{s 1}}{\partial x_{s 1}{ }^{2}}<0$ and $\frac{\partial^{2} \Pi_{s 2}}{\partial x_{s 2}{ }^{2}}<0$ yields $0 \leq \beta<\frac{1}{2}(2-\sqrt{2})$ and $\theta>\frac{1}{16}\left(9-12 \beta+4 \beta^{2}\right)$; or $\frac{1}{2}(2-\sqrt{2})<\beta \leq 1$ and $\theta>\frac{1}{8}\left(4-4 \beta+\beta^{2}\right)$. Under this condition, the game has an equilibrium solution. We then obtain the FONC equations of $\Pi_{s 1}$ and $\Pi_{s 2}$ about $x_{s 1}, x_{s 2}$ which are complex polynomials of long length. No closed solutions for $x_{s 1}$, $x_{s 2}$ can be found from these expressions though we know that equilibrium $x_{s 1}, x_{s 2}$ will be achieved when both suppliers earn zero profits. Substituting expressions of $q_{s 1}, q_{s 2}$ into $\Pi_{O B}$ yields the overseas buyer's profit expressed by $x_{s 1}, x_{s 2}$ as:

$$
\begin{aligned}
& \Pi_{O B}\left(x_{s 1}, x_{s 2}\right)= \\
& \frac{1}{4}\left(A-A_{1}\right)\left(3 A_{1}+x_{s 2}-3 \alpha+2 x_{s 2} \beta+x_{s 1}(2+\beta)\right) .
\end{aligned}
$$

Therefore, Proposition 3 holds.

Proof of Proposition 4. Through similar approach as in 4.1, we can prove that when $\theta>\frac{1-\beta}{2}+\frac{\sqrt{1-4 \beta+4 \beta^{2}}}{2 \sqrt{2}}$, the concavity of profit functions in each stages can be satisfied and the game has equilibrium outcome. We then apply (27) into (25)-(26) and solve the FONC conditions about $x_{s 1}, x_{s 2}$ to obtain: $x_{s 1}=\frac{q_{s 1}}{2 \theta}, x_{s 2}=\frac{q_{s 2}}{2 \theta}$.

Substituting the above equations and (27) into (24), and solving the FONC conditions about $q_{s 2}$ yields: $q_{s 2}=\frac{q_{s 1} \beta+2 A_{1} \theta-2 q_{s 1} \theta-2 \alpha \theta}{-1+4 \theta}$, Then we apply the value of $q_{s 2}$ into (23) and obtain: $q_{s 1}=\frac{2\left(A_{1}-\alpha\right) \theta(-1+\beta+2 \theta)}{1-2 \beta^{2}-8 \theta+8 \beta \theta+8 \theta^{2}}$. Through backward induction we obtain the value of all objective expressions. The overseas buyer's profit is proved to be $\frac{2\left(A-A_{1}\right)\left(A_{1}-\alpha\right) \theta\left(2-2 \beta-\beta^{2}-12 \theta+12 \beta \theta+12 \theta^{2}\right)}{(-1+4 \theta)\left(1-2 \beta^{2}-8 \theta+8 \beta \theta+8 \theta^{2}\right)}$, total innovation output in the suppliers cluster is $\frac{\left(A_{1}-\alpha\right)\left(2-2 \beta-\beta^{2}-12 \theta+12 \beta \theta+12 \theta^{2}\right)}{(-1+4 \theta)\left(1-2 \beta^{2}-8 \theta+8 \beta \theta+8 \theta^{2}\right)}$, and total profit of the cluster is:

$$
\begin{aligned}
& \frac{\theta\left(A_{1}-\alpha\right)^{2}}{(4 \theta-1)\left(1-2 \beta^{2}-8 \theta+8 \beta \theta+8 \theta^{2}\right)^{2}}\left(-2+\beta^{4}+24 \theta-88 \theta^{2}\right. \\
& +112 \theta^{3}-48 \theta^{4}+2 \beta^{3}(-3+8 \theta)+\beta^{2}\left(2+20 \theta-88 \theta^{2}\right)-4 \beta . \\
& \left.\left(-1+14 \theta-46 \theta^{2}+32 \theta^{3}\right)\right)
\end{aligned}
$$

Therefore, Proposition 4 holds.

Proof of Proposition 5: Taking the intersection of the concave conditions in Proposition 1-4, we obtain (a) and (b) as the conditions for four models to be compared. Note from Proposition 1-4 that, $X_{S 1 S 2}^{V P}$ are obtained when both suppliers' innovation are the larger roots of zero profit function. $X_{S 1 S 2}^{V W}$ are obtained when both suppliers maximum their profit. Given that suppliers' profit functions are concave about their innovation, we obtain that $X_{S 1 S 2}^{V P}>X_{S 1 S 2}^{V W}$. 
The result of Proposition 5(2) is obtained by direct comparison of optimal solutions in case VWCC and VWCB:

$$
\begin{aligned}
& X_{S 1 S 2}^{V W C C}-X_{S 1 S 2}^{V W C B}=\frac{1}{2} \\
& \frac{\left(A_{1}-\alpha\right)(\beta-2 \theta)^{2}(-1+\beta+2 \theta)}{(1+\beta-6 \theta)(-1+4 \theta)\left(-1+2 \beta^{2}+8 \theta-8 \beta \theta-8 \theta^{2}\right)} . \\
& >0
\end{aligned}
$$

Therefore, Proposition 5 holds.

Proof of Proposition 8. Taking intersection of equilibrium conditions from Proposition $1-4$, we obtain the following set as the condition for comparisons of the four models:

(a) $0 \leq \beta<\frac{1}{2}(2-\sqrt{2})$ or $\frac{1}{2}(2-\sqrt{2})<\beta<-2 \sqrt{2}+\sqrt{2(4+\sqrt{2})}$; or $2 \sqrt{2}-\sqrt{2(4-\sqrt{2})}<\beta \leq 1$, with $\theta>\frac{1-\beta}{2}+\frac{\sqrt{1-4 \beta+4 \beta^{2}}}{2 \sqrt{2}}$.

(b) $\sqrt{2}(-2+\sqrt{4+\sqrt{2}})<\beta<-\sqrt{2}(-2+\sqrt{4-\sqrt{2}})$ with $\theta>\frac{1}{8}\left(4-4 \beta+\beta^{2}\right)$. 